\title{
SAIR DA ÁFRICA PARA ESTUDAR NO BRASIL: FLUXOS EM DISCUSS ÃO
}

\author{
DEJAR ÁFRICA PARA ESTUDIAR EN BRASIL: FLUJOS EN DISCUSIÓN
}

LEAVING AFRICA TO STUDY IN BRAZIL: FLOWS IN DEBATE

http://dx.doi.org/10.1590/1807-0310/2017v29162231

Luciana de Sousa Lima

Universidade do Porto, Porto, Portugal

Giulliany Gonçalves Feitosa

Universidade Federal de Campina Grande, Campina Grande/PB, Brasil

\begin{abstract}
RESUMO
Trata-se de um estudo exploratório de natureza qualitativa, orientado pelo construcionismo social e pela psicologia social discursiva. Teve como principal objetivo analisar os significados que circunscrevem a experiência migratória para fins de estudo através dos relatos de africanos(as) vinculados(as) ao Programa de Convênio Estudantil- PEC-G numa universidade localizada no interior do Nordeste brasileiro. Foi realizada observação participante durante seis meses e entrevistas semiestruturadas com oito acadêmicos. As construções discursivas sinalizaram que a migração era uma forma de adquirir formação acadêmica em outro país; nesse sentido, o PEC-G facilitava a concretização desse projeto migratório, além de ser vantajoso por possibilitar o acesso ao ensino superior gratuito, também representava possibilidade de promoção social. Nesse deslocamento, em que há um projeto individual e familiar evidente, os estudantes tiveram contato com outras visões de mundo e comportamentos que lhes permitiram elaborar novos significados, colaborando assim no processo de adaptação.
\end{abstract}

Palavras-chave: migração; ensino superior; africanos.

\section{RESUMEN}

Presentamos aquí un estudio exploratorio cualitativo guiado por el construccionismo social y la psicología social discursiva. Su principal objetivo es analizar los significados que cirscuncriben a la experiencia migratoria de los estudiantes africanos vinculados al programa PEC-G. Esta investigación se realizó en una universidad del Nordeste del Brasil, utilizando observación participante durante seis meses y entrevistas semiestructuradas con ocho individuos académicos. Las construcciones discursivas señalaron que la migración es un modo de adquirir la formación académica en otro país, en este sentido el PEC-G facilitó la realización de este proyecto de migración, Además de ser ventajoso por permitir el acceso a la educación superior gratuita, también representa la posibilidad de promoción social. En este desplazamiento, en el que hay un proyecto individual y familiar evidente, los estudiantes tuvieron contacto con otras visiones del mundo y comportamientos que les permitieron elaborar nuevos significados, colaborando así en el proceso de adaptación.

Palabras-clave: migración; educación superior; africanos.

\begin{abstract}
Here we present an exploratory qualitative study guided by social constructionism and discursive psychological approach. Its main objective is to analyze the meanings around the migratory experience on African students linked to the PEC-G partnership program. This research took place at a Northeast Brazilian university, using participant observation for six months and semi-structured interviews with eight academic individuals. Among the main results we highlight the facilitated access to higher education through PEC-G (at a low cost in Brazil) as well as the aspiration of social promotion. Within this process there's an evidence of individual and family investment, the contact with other worldviews and behaviors that enable them to elaborate new meanings, and playing an influence on their process of adaptation.
\end{abstract}

Keywords: migration; higher education; africans. 


\section{Introdução}

O fluxo migratório para fins de qualificação acadêmica, apesar de não ser um fenômeno recente, vem ganhando notoriedade nas pesquisas sociais, sobretudo por ser cada vez mais frequente, complexo e passível de múltiplas análises (Brooks \& Waters, 2011; Olwig \& Valentin, 2015). Configura-se como migração temporária, uma vez que há um tempo previamente estipulado de permanência no país de destino (Desidério, 2006; Gusmão, 2012).

Embora o Brasil não tenha expressividade em termos de números de matrículas de estudantes internacionais se comparado com os países da América do Norte e da Europa Ocidental e esteja ainda numa fase embrionária no processo de internacionalização da educação superior (Castro \& Cabral, 2012; Peixoto, 2010), a presença de latino-americanos(as) e africanos(as) nas universidades brasileiras revela um cenário diferenciado de migração temporária para fins de estudo, tendo em vista que muitos desses estudantes são oriundos de países cujo sistema de ensino superior é recente e/ou precário e vêm através de acordos educacionais bilaterais entre o Brasil e aqueles países (Desidério, 2006; Gusmão, 2009; Nhaga, 2013).

Dentre esses acordos educacionais, o Programa Estudante Convênio de Graduação (PEC-G), desenvolvido pelo governo brasileiro, destaca-se por possibilitar a vinda de um número considerável de estudantes estrangeiros(as) desde a década de 60, sobretudo nacionais africanos (Ministério das Relações Exteriores, 2015). Segundo dados do Ministério das Relações Exteriores entre os anos 2000 e 2015, por exemplo, o PEC-G selecionou 6.761 africanos(as) e 1.939 latino- americanos(as) e caribenhos(as).

Para além dos números que indicam a presença desses(as) estrangeiros(as) nas universidades brasileiras, há nesse tipo de migração inúmeras possibilidades de problematizações que carecem de maior visibilidade e análise nas pesquisas sociais. De fato, há escassez de estudos que analisam a importância histórica, política e social dos acordos educacionais e culturais estabelecidos entre Brasil e África (Desidério, 2006; Gusmão, 2006, 2009, 2012; Mourão, 2004; Subuhana, 2005, 2009), bem como outras questões relacionadas à integração desses estudantes nas instituições brasileiras (Andrade \& Teixeira, 2009) e os sentidos e significados que estudantes internacionais atribuem às suas experiências de estudar no Brasil.

Apesar de haver grandes contribuições na discussão sobre migrações no campo da psicologia (Berry, 2004, 2005, 2006; Brisset et al, 2010; Sarriera,
2000; Wilks \& Monteiro, 2016), identificamos poucas pesquisas com estudantes internacionais no contexto brasileiro. Dentre os estudos consultados (Albuquerque, 2016; Andrade \& Teixeira, 2009; Sarriera et al., 2002), destacamos a investigação de Andrade e Teixeira (2009) que objetivou avaliar o índice de adaptação e integração do(a) aluno(a)-convênio matriculado(a) na Universidade Federal do Rio Grande do Sul. Os autores indicaram a importância de se prestar serviços de assistência mais eficientes a esses(as) alunos(as) e o desenvolvimento de outros estudos no campo da psicologia sobre o(a) estudante-convênio no contexto nacional.

Nessa perspectiva e com o intuito de dar notoriedade ao fenômeno migratório para fins de estudo no contexto brasileiro a partir de uma leitura construcionista social (Gergen, 1994; Gergen \& Gergen, 2011; Nogueira, 2001), a qual considera que "as ideias, os conceitos e as memórias surgem do intercâmbio social e são mediatizados pela linguagem" (Nogueira, 2001, p. 49), desenvolvemos em 2014 um projeto de iniciação científica cujo interesse centravase nos significados elaborados sobre a experiência migratória de africanos(as) vinculados(as) ao Programa Estudante Convênio de Graduação (PEC-G) matriculados(as) numa universidade localizada no Nordeste brasileiro.

Nesse sentido, apresentaremos aqui os resultados do nosso estudo exploratório que objetivou analisar os significados que circunscrevem a experiência migratória para fins de estudo através dos discursos do grupo supracitado. Mais especificamente objetivamos: i) observar como acontecia a interação entre estudantes africanos(as) e brasileiros(as); ii) identificar as razões de terem escolhido o Brasil para estudar; e iii) analisar os significados que os(as) estudantes-convênio elaboravam sobre os seus cotidianos acadêmicos e extra-acadêmicos.

A referência do espaço geográfico de destino, nesse caso estudantes que se deslocam para o Nordeste brasileiro, é um elemento importante a ser considerado não só por causa do fluxo migratório de africanos(as) ser menor naquela região se comparado ao Sul e Sudeste do país, mas também pelos aspectos sociais e culturais desse local que podem interferir positiva ou negativamente na adaptação do(a) estudante africano(a) (Nilsson \& Anderson, 2004 citados por Andrade \&Teixeira, 2009).

Portanto, trata-se de uma pesquisa de natureza qualitativa cuja abordagem teórico-metodológica segue a orientação do construcionismo social (Gergen, 1994; Gergen \& Gergen, 2011; Nogueira, 2001) e da psicologia social discursiva (Potter, 1998; Potter \& 
Wetherell, 1987; Wetherell \& Potter, 1992). Partimos do pressuposto de que a forma como definem e percebem a experiência migratória deve ser analisada inicialmente pela elaboração de significados em função do contexto em que estavam inseridos (Nogueira, 2001).

\section{Método}

\section{Caracterização dos participantes}

De acordo com a lista encaminhada pela PróReitoria de Ensino da instituição onde desenvolvemos a pesquisa, em 2014 havia 18 estudantes africanos(as) vinculados(as) ao PEC-G, distribuídos em diferentes campi. Pelos dados oficiais fornecidos, 12 discentes estavam matriculados(as) no campus principal da instituição, local da coleta de dados. Todavia, fomos informadas pelos estudantes africanos que dois discentes da lista já tinham concluído seus cursos e/ ou foram transferidos(as); quanto aos outros dois, não conseguimos seus contatos em tempo hábil, fato que reduziu nossa amostra para oito participantes.

A amostra só apresentava uma mulher. Suas idades variavam entre 19 e 27 anos. No momento da coleta de dados, apenas três dos entrevistados recebiam bolsas de estudos do governo brasileiro ${ }^{1}$. Eram de diferentes nacionalidades, sendo quatro países de língua oficial portuguesa, a saber: Cabo Verde, Angola, Moçambique e São Tomé e Príncipe; e dois países de língua oficial francesa: Benin e Camarões. A nacionalidade predominante no grupo foi a caboverdiana, com dois entrevistados (ver Tabela 1).

No que diz respeito à inserção nas áreas acadêmicas, seis participantes estavam inscritos em cursos de áreas exatas e tecnológicas. Além disso, o ano de ingresso e previsão de conclusão indica que a maioria estava há menos de cinco anos no país, exceto o estudante cabo-verdiano de Engenharia Mecânica que chegou em 2008. Segundo esse estudante, ele estava bastante atrasado porque reprovou em algumas disciplinas do curso. Havia ainda dois africanos recém-chegados ao país no momento da entrevista, no primeiro semestre de 2015, conforme ilustrado na Tabela 1.

\section{Instrumentos e procedimentos}

Sendo esta investigação o resultado de um projeto de iniciação científica, a operacionalização da coleta de dados perpassou pelos seguintes passos: submissão

Tabela 1. Caracterização dos participantes da pesquisa

\begin{tabular}{|c|c|c|c|c|c|}
\hline Nacionalidade & Idade & Sexo & $\begin{array}{c}\text { Meios de subsistência } \\
\text { no Brasil }\end{array}$ & $\begin{array}{c}\text { Curso que } \\
\text { Frequentavam }\end{array}$ & $\begin{array}{l}\text { Ano de Ingresso } \\
\text { e Previsão de } \\
\text { Conclusão }\end{array}$ \\
\hline $\begin{array}{l}\text { São Tomé e } \\
\text { Príncipe }\end{array}$ & $\begin{array}{c}23 \\
\text { anos }\end{array}$ & Masculino & $\begin{array}{l}\text { Bolsa de estudos- } \\
\text { PROMISAES }\end{array}$ & $\begin{array}{c}\text { Ciências } \\
\text { Econômicas }\end{array}$ & 2014.1- 2018.1 \\
\hline Guiné- Bissau & $\begin{array}{c}24 \\
\text { anos }\end{array}$ & Masculino & Recursos próprios & $\begin{array}{l}\text { Ciências da } \\
\text { Computação }\end{array}$ & 2014.1- 2018.1 \\
\hline Angola & $\begin{array}{c}23 \\
\text { anos }\end{array}$ & Masculino & Recursos próprios & $\begin{array}{l}\text { Engenharia de } \\
\text { Petróleo }\end{array}$ & 2011.1- 2015.1 \\
\hline Cabo Verde & $\begin{array}{c}27 \\
\text { anos }\end{array}$ & Masculino & $\begin{array}{c}\text { Bolsa auxílio moradia } \\
\text { da universidade }\end{array}$ & $\begin{array}{l}\text { Engenharia } \\
\text { Mecânica }\end{array}$ & 2008.1- 2012.1 \\
\hline Cabo Verde & $\begin{array}{c}20 \\
\text { anos }\end{array}$ & Masculino & Recursos próprios & Engenharia Civil & 2015.1- 2019.1 \\
\hline Camarões & $\begin{array}{c}27 \\
\text { anos }\end{array}$ & Feminino & $\begin{array}{l}\text { Bolsa de estudos- } \\
\text { PROMISAES }\end{array}$ & Letras & 2012.1-2015.2 \\
\hline Benin & $\begin{array}{c}20 \\
\text { anos }\end{array}$ & Masculino & Recursos próprios & Engenharia Agrícola & $2015.1-2019.2$ \\
\hline Moçambique & $\begin{array}{c}19 \\
\text { anos }\end{array}$ & Masculino & $\begin{array}{l}\text { Bolsa de estudos- } \\
\text { PROMISAES }\end{array}$ & $\begin{array}{l}\text { Arquitetura e } \\
\text { Urbanismo }\end{array}$ & 2014.2- 2019.1 \\
\hline
\end{tabular}


do projeto junto ao Comitê de Ética; reuniões para discussão do referencial teórico-metodológico; melhoria do guia de entrevistas após revisão da literatura; e treinamento prévio da pesquisadora responsável pela ida a campo.

Após a primeira etapa, fomos à Coordenação de Programas e Estágios vinculada à Pró-Reitoria de Ensino da instituição, órgão responsável pela matrícula desses discentes. Nessa ocasião, forneceram-nos uma lista com os nomes desses estudantes, número de matrícula com indicação do campus universitário, nacionalidades, curso que frequentavam, ano de ingresso e provável conclusão. Contudo, na lista não havia contato telefônico, nem endereço eletrônico dos(as) estudantes-convênio; no entanto, uma das pesquisadoras conhecia um estudante africano que mediou o encontro com grande parte dos(as) estudantes que estavam na lista.

Em seguida, foi realizada observação participante entre os meses de novembro de 2014 e maio de 2015 no campus universitário. Nessa ocasião, nos aproximamos dos espaços frequentados simultaneamente pelos(as) estudantes africanos(as) e brasileiros(as) e a partir daí identificamos como essas interações aconteciam. As impressões dessa observação foram registradas em um diário de campo.

Também foi realizada entrevista semiestruturada com os oito participantes. Após a ida a campo e de acordo com o referencial bibliográfico e nossas questões de pesquisa, elaboramos um roteiro com perguntas que versavam sobre o significado de estar numa universidade brasileira, a escolha do Brasil para estudar, adaptação no país e na universidade, formas de subsistência, redes de apoio no país e projetos futuros. As entrevistas tiveram uma duração média de 30 minutos e foram realizadas em salas de aula vazias da instituição de ensino. Todas foram gravadas em aparelho de captação de áudio e transcritas. Antes da entrevista, foi apresentado o termo de consentimento livre e esclarecido que foi assinado por todos.

Para o processo de análise, utilizamos o método de análise de discurso desenvolvido pelos teóricos da psicologia social discursiva (Potter, 1998; Potter \& Wetherell, 1987; Wetherell \& Potter, 1992). Segundo essa abordagem, muito mais do que aquilo que as pessoas são ou dizem ser, o fundamental é compreender como essas pessoas utilizam certos discursos para narrarem e construírem um sentido para as situações que o(a) analista de discurso thes propõe explorar (Nogueira, 2006).

Ancoradas nessa perspectiva, na pré-análise preocupamo-nos com a familiarização dos dados, dando atenção às falas no momento da transcrição das entrevistas. Em seguida fizemos a primeira codificação, isto é, uma análise preliminar que teve por objetivo organizar as categorias produzidas pelas questões da pesquisa, etapa que permitiu uma leitura mais minuciosa e atenta aos detalhes dos discursos. Após essa primeira codificação foi possível identificar padrões na linguagem que possibilitaram perceber os significados que elaboravam sobre suas experiências no contexto que estavam inseridos e aquilo que deixavam emergir nas entrelinhas de suas construções discursivas. Esses padrões foram organizados em temas de análise que serão apresentados a seguir.

\section{Resultados e discussão}

Ao longo da observação foi possível verificar que os africanos e a africana andavam em grupo com seus conterrâneos ou sozinhos(a). Durante o intervalo das aulas, e principalmente no horário do almoço, era comum vê-los reunidos. Outro fato perceptível foi o distanciamento entre brasileiros(as) e africanos(as). Um desses, o entrevistado de Cabo Verde que está há mais tempo na instituição, falou que, às vezes, alguns brasileiros sentados nos bancos da praça iam embora quando os africanos se aproximavam. Dentro do Restaurante Universitário também foi possível perceber esse distanciamento, já que os estudantes africanos e a africana almoçavam juntos, ou então, quando não estavam em grupo, almoçavam sozinhos. Raramente havia interação com brasileiros(as) nesse espaço.

Em alguns estudos consultados, a dinâmica acima descrita foi também verificada (Nhaga, 2013; Subuhana, 2005, Tcham, 2012). De acordo com a análise de Tcham (2012) ao referir-se à sociabilidade de estudantes africanos(as) em duas instituições de ensino localizadas em capitais nordestinas (Maceió e Recife), o desconhecimento da África e dos(as) africanos(as) por parte dos(as) brasileiros(as) cria uma representação mítica do continente e de sua população que distanciam nativos e africanos(as). Além disso, a dificuldade de comunicação devido aos sotaques e dialetos dos seus respectivos países geram uma rede limitada de relacionamento e de diálogo entre aqueles estrangeiros(as) e brasileiros(as).

Por outro lado, Mourão (2009) argumenta que a união ou oposição entre grupos depende da situação e das relações que são estabelecidas em função de algum acontecimento. Nessa perspectiva, acreditamos que a união do grupo observado estava relacionada ao fato de serem estudantes-convênio e oriundos de um mesmo continente, como também pelo apoio que davam um ao outro, sobretudo no momento da chegada 
à universidade. Em algumas entrevistas foi possível ver os argumentos que utilizavam para justificar a união do grupo:

Quando eu me sentia só, B.N (um colega africano do PEC-PG) me apoiava, dizia "vai, tudo pode ser difícil, mas mais difícil foi deixar a familia lá, isso aqui é fácil para você". Ai vai a força dos amigos que agora trato como familia. (Entrevistado de GuinéBissau, 24 anos)

Quando eu cheguei aqui já tinha outros estudantes de convênio aqui, ai eles me receberam aqui e ai não foi muito difícil essa fase de adaptação. (Entrevistado de Cabo Verde, 27 anos)

Nhaga (2013) afirma que um estudante ao chegar ao Brasil é acolhido dentro da universidade pela comunidade de estudantes africanos(as) que nela se encontra; são os veteranos(as) que auxiliam os(as) novatos(as) na adaptação, inclusive na resolução de problemas enfrentados no ato da chegada à universidade, como entrega de documentos e cadastro na biblioteca. Ainda de acordo com Nhaga, essa primeira experiência acadêmica é crucial, pois a partir dela alguns estudantes podem permanecer ou desistir do curso antes mesmo de iniciá-lo. A fala do entrevistado de Angola, A. S., simboliza bem como os meses que sucedem a chegada ao país são os de maior vulnerabilidade emocional, e a ajuda dos pares é fundamental para superar isso: "Eu olhava para universidade e me perguntava: meu Deus, onde é que eu tô? Eu tinha tudo para ficar em depressão, mas não, eu consegui me manter em pé, sabe?".

Relativamente às ações discursivas através das quais os entrevistados e a entrevistada definiam o seu percurso e suas percepções sobre seus cotidianos acadêmicos e extra-acadêmicos, interagindo com nacionais brasileiros, permitiram elencarmos os seguintes temas de análise: i) PEC- G e o acesso ao ensino superior em país estrangeiro; ii) o estar na universidade como privilégio e como projeto; e iii) o convívio com o diferente e os significados elaborados a partir desse contato. Estes serão discutidos em subseções a seguir.

\section{PEC-G e o acesso ao ensino superior em país estrangeiro}

Alguns relatos dos entrevistados e da entrevistada indicam-nos que a gratuidade do ensino superior e a oportunidade de estudar em um país estrangeiro com todas as vantagens que essa migração pode trazer, como aprender uma nova língua e conhecer outra cultura, são fatores importantes na escolha do Brasil para estudar, conforme está descrito abaixo:
Passei um mês a estudar em uma universidade antes de vir praqui ... lá tem, mas... é mais burocrático (Entrevistado de São Tomé e Príncipe, 23 anos)

tenho amigos e primos que já estudavam aqui ... e também na verdade eu sempre quis sair do país, estudar fora, conhecer a realidade de outro povo e adquirir conhecimento ... E no meu país não tem universidades públicas assim ... (Entrevistado de Guiné-Bissau, 24 anos)

Na verdade não foi uma escolha minha ... E é difícil poder entrar num instituto superior de petróleo lá em Angola. Você tem que ter muita influência. ... Fiquei dois anos seguidos tentando entrar numa universidade em Angola e não deu certo ... aí um dos meus tios descobriu que a embaixada brasileira estava com um programa de bolsas e chamou ... não foi um chamado só, foi uma obrigação. (Entrevistado de Angola, 23 anos)

Porque contaram novidades quando eu estava lá em Cabo Verde, antes de vir para cá. Já tinha pesquisado acerca de informações sobre a universidade daqui. E meu professor sempre me estimulou assim que aqui é um lugar certo pra fazer engenharia. (Entrevistado de Cabo Verde, 27 anos)

Escolhi o Brasil pra estudar porque lá em Cabo Verde tem o programa PEC-G que os estudantes vêm pra cá e só terão despesa com moradia e alimentação, então é uma oportunidade porque lá em Cabo Verde temos que pagar as universidades para estudar e aqui, de acordo com esse programa, não vamos ter que pagar as universidades. Isso é vantajoso. (Entrevistado de Cabo Verde, 20 anos)

Ah, não sei! Na verdade não escolhi mesmo ... Eu ia terminar minha graduação, ai tava preocupada com o que fazer. Eu não queria fazer mestrado, eu queria dar uma pausa, viajar para visitar outros países. (Entrevistada de Camarões, 27 anos)

Porque queria aprender outra lingua. (Entrevistado de Benin, 20 anos)

Primeiro por ser uma língua do meu país. Dois, por eu gostar muito do Brasil, sempre gostei. E pelas indicações, tem boas faculdades, bom ensino. (Entrevistado de Moçambique, 19 anos)

Conforme dito anteriormente e confirmado em algumas falas acima, em alguns países africanos o sistema de ensino superior não é acessível a todos os seus nacionais, sobretudo pelo valor das mensalidades que representa para muitas famílias um alto investimento. Fora isso, o legado colonial de baixo investimento em educação em muitas ex-colônias africanas dificultou a criação de universidades e ensinos politécnicos, ocasionando pouca oferta de vagas e cursos (Tolentino, 2006). De certa forma, aquilo que aparentemente é 
uma migração que atende aos preceitos de um mundo globalizado na verdade parece configurar-se como uma migração provocada pelas deficiências do sistema educacional nas ex-colônias.

Há também nessa migração a possibilidade de estudar no Brasil, o país que além de oferecer vagas nas universidades brasileiras através do PEC-G tinha, em seus discursos, potencial no que se refere à oferta de emprego e/ou continuidade dos estudos. De acordo com alguns entrevistados:

Depois de terminar tudo, olha... não vou terminar só a graduação, porque ao terminar a graduação eu faço o mestrado e ir direto pro meu país de novo, a não ser que apareça qualquer oportunidade aqui muito boa, eu fico mesmo aqui, por que eu acho aqui bom pra viver. (Entrevistado de São Tomé e Príncipe, 23 anos)

Brasil é um bom país pra viver, eu posso viver tranquilo aqui ... Assim, tô pensando em fazer mestrado, sei que fazer mestrado e doutorado é muito bom. Mas assim, voltar para casa até hoje eu tô pensando... se eu conseguir um bom emprego eu posso morar aqui de boa.(Entrevistado de Guiné Bissau, 24 anos)

É... um país de oportunidades. Eu tenho no meu contrato que depois de terminar o curso tenho que voltar pra poder levantar meu diploma em Angola. Mas eu tenho duas opções. Eu vejo o Brasil um país tão fértil ... Então, é um país que vale a pena. É um país que vale a pena investir, é um país do futuro. Eu diria isso e concordo com quem diz isso. (Entrevistado de Angola, 23 anos)

Meus planos é obviamente voltar pra meu país pra cumprir os cinco anos, mas se não fosse por isso eu até que ficava aqui no seu país que é muito legal. (Entrevistado de Moçambique, 19 anos).

Apesar de se comprometerem a voltar para o país de origem após o término da graduação, a permanência no Brasil passa a ser anunciada. Se por um lado o governo brasileiro possibilita a continuidade dos estudos através do Programa Estudante Convênio de Pós-Graduação (PEC-PG), por outro lado o retorno pode colocá-los diante das dificuldades de oferta de emprego nos seus países de origem. São dilemas que muitos(as) estudantes de países com alta taxa de desemprego enfrentam.

Em tese, os clichês "país de oportunidades", "bom para viver", "o país do futuro" associados à imagem do Brasil pelos entrevistados acima eram adotados em seus discursos pelo fato de, naquele momento, estarem em contato com essa linguagem reproduzida no contexto em que estavam inseridos, como bem lembrou o entrevistado de Angola "eu diria isso e concordo com quem diz isso". Nessas condições, a ideia de "país fértil", de "país que vale a pena investir" fazia sentido para esses estudantes, sobretudo por estarem convivendo cotidianamente com esses discursos.

Nos relatos foi possível perceber também que suas famílias, além de incentivarem os filhos(as) a prosseguir nos estudos como relatado pelo entrevistado de Angola: "Tipo, antes de eu vir pra cá e desde que eu tô aqui, sempre recebi total apoio e incentivo dos meus pais", possuem condição econômica suficiente para mantê-los no Brasil, mesmo porque, segundo as regras do PEC-G, as famílias devem assinar um termo de compromisso garantindo o envio de, no mínimo, 400 dólares mensais (Ministério das Relações Exteriores, 2015).

\section{O estar na universidade como privilégio e como projeto}

Para esses estudantes-convênio que vêm de países africanos em desenvolvimento e com graves problemas sociais, a possibilidade de ter elevados índices de escolaridade coloca-os em uma posição privilegiada em relação aos seus conterrâneos com baixos níveis de formação escolar. Essa condição de privilegiados não era anunciada de forma explícita por nossos interlocutores e interlocutora, estava mais nas entrelinhas dos discursos, principalmente quando se referiam à importância de estar na universidade:

Acho isso o início de tudo. Para que eu tenha minha vida e concretizar todos os meus sonhos que eu pretendo. Porque assim formado eu vou poder fazer tudo que eu penso e ser independente, principalmente da minha familia. (Entrevistado de Guiné-Bissau, 24 anos)

Tem sempre aqueles que se orgulham em saber que provavelmente terão um amigo engenheiro. E aí eu só recebo incentivos, eu gosto disso ... tem aquela questão de chegar a ter um status, sabe? Dá até pra ficar se exibindo "sou um estudante universitário, olha a'”, é uma coisa legal. Eu prefiro encarar isso como um projeto de vida, algo que vai abrir as portas pro que eu quero fazer no futuro. (Entrevistado de Angola, 23 anos)

Eu diria muito bom mesmo, principalmente na minha área, como você já sabe, aqui a área de engenharia é uma das mais conceituadas no Brasil, na América, eu diria. (Entrevistado de Cabo Verde, 27 anos)

Estar na universidade é algo muito... é um objetivo muito grande, ao mesmo tempo orgulho, né? De estar na universidade e principalmente estar na universidade fora do meu país que faz com que eu tenha mais ambição, mais foco e com o objetivo, o compromisso de voltar já formado. (Entrevistado de Moçambique, 19 anos) 
Ao "ser o início de tudo", "abrir as portas pro que eu quero fazer no futuro", "uma das mais conceituadas", "um objetivo muito grande", o acesso à universidade parece estar relacionado às ambições pessoais e, ao mesmo tempo, à possibilidade de promoção social, algo que não seria possível se permanecessem em seus países sem estudar.

Por sua vez, quando o entrevistado de Moçambique diz que tem "o compromisso de voltar já formado" ou quando assume para si o retorno como um dever, "eu volto para cumprir o dever de trabalho de cinco anos", deixa implícita a provisoriedade da sua permanência no país de destino e o compromisso que assume, de forma consciente ou não, com seu país de origem.

Mesmo que os estudantes cogitem ficar no Brasil para trabalhar ou dar continuidade aos estudos, conforme apresentado na subseção anterior, esses estudantes-convênio deixam subentendidos em seus discursos que fazem parte de um projeto nacional de desenvolvimento em seus respectivos países de origem, já que devem voltar qualificados e, na melhor das hipóteses, utilizar seus conhecimentos em benefício de suas nações (Gusmão, 2008). Dessa forma, não podemos nos esquecer de que, no interior desse jogo de interesses em que há um projeto individual e familiar evidente, há também "esforços para ampliar as relações exteriores entre países em desenvolvimento que atende a uma agenda mundial de interesses e pela ajuda mútua objetiva-se o alcance das metas do milênio que os chefes de governo assinam e se comprometem a melhorar seus indicadores" (Desidério, 2005, p. 13).

\section{O convívio com o diferente e os significados elabo- rados a partir desse contato}

Foi possível identificar nos relatos desses estudantes o que representava estar numa cidade de pequeno porte e numa região que tinha suas vantagens se comparada às outras regiões de maior fluxo de africanos(as), especificamente o Sul e o Sudeste do país:

Aqui é um pouco mais calmo em relação a outras cidades que eu conheço, aqui é uma cidade mais universitária. Não tem muitos lugares pra sair em relação a outras cidades mais grandes, ai a pessoa acaba se acostumando mais, as pessoas são de fora, rola aquele intercâmbio ... Mesmo aqui no Brasil existem diferenças entre cidades, até na fala um pouco diferente... entre Norte, Sul, Nordeste... Tipo, o Sul acha que eles são donos do Brasil, aí... mas... é normal. (Entrevistado de Guiné-Bissau, 24 anos)

Porque quando eu cheguei eu fiquei uma semana em São Paulo antes de vir praqui e eu notei a diferença entre o sotaque paulista e o daqui do norte-nordeste. E aqui entrava em conflito com o meu jeito de falar, sabe? Tanto que quando cheguei aqui encontrei um cara logo na entrada e perguntei "meu, qual é o teu curso?" e ele disse "eu não entendi o que você falou”. Eu disse "qual é o teu curso?” e eu "droga meu! Eu falo português e ele não entende!” (risos). (Entrevistado de Angola, 23 anos)

Porque aqui, por exemplo, a cidade é parecida praticamente com a minha terra lá em Cabo Verde. É parecido, ah... não teve muita mudança. Talvez se eu estivesse em São Paulo sentiria mais mudança porque é cidade maior, mas aqui é praticamente igual à cidade lá em Cabo Verde. (Entrevistado de Cabo Verde, 20 anos)

Em São Paulo eu não posso dizer que percebi alguma coisa, mas quando eu cheguei aqui fui na casa da cultura, que aqui vão os índios, explicaram um pouquinho da história brasileira, e fui conhecendo... conhecendo também que não tem só mulheres que andam peladas na praia, até que eu vi isso, mulheres de fio dental na praia e fiquei "oh! Meu Deus do céu, isso existe?"(Entrevistada de Camarões, 27 anos)

As percepções dos estudantes e da estudante sobre a cidade em que residiam partiam de comparações com cidades brasileiras que já tinham visitado ou com seus países de origem. Eram percepções que também estavam associadas à linguagem reproduzida em seus cotidianos, quando, por exemplo, o entrevistado de Guiné-Bissau relatou algo comumente falado entre nordestinos: "tipo, o Sul acha que eles são donos do Brasil".

Ao relatarem que a cidade era "um pouco mais calma", onde "as pessoas são de fora, rola aquele intercâmbio" e muito parecida com a terra de origem, alguns expressavam as qualidades e vantagens de ali estar, o que, de certa forma, ajudava-os no processo de adaptação. Por outro lado, também emitiam os conflitos gerados a partir do contato com um contexto diferente. Nos fragmentos "E aqui entrava em conflito com o meu jeito de falar, sabe?" ou "oh! Meu Deus do céu, isso existe?" fica explícito como esses contatos lhes faziam questionar as diferenças ou confirmar suas hipóteses sobre a terra estrangeira.

$\mathrm{Na}$ medida em que falavam desse espaço territorial e de seus cotidianos na academia e fora dela, nomeavam as diferenças culturais que observavam nos seus cotidianos:

Principalmente a cena de... homossexualidade. Isso mexeu com meu psicológico muito, porque lá não se vê o que se vê aqui. Demorou um pouco para habituar a cultura. E quando presenciei isso fiquei meio que espantado assim... com um tempo fui me habituando assim, comecei a meter esse pensamento no meu 
pensamento. (Entrevistado de São Tomé e Príncipe, 23 anos)

A cultura de lá e a daqui é um pouco diferente. Lá tem mais a cultura antiga, de dizer "filho", quando você está na casa dos pais você se sente obrigado a respeitar e mesmo saindo, pai é pai e isso fica por certo, e os mais velhos também têm que respeitar mesmo conhecendo ou não. E aqui, eu cheguei aqui... assim... nada contra, mas aqui já é um pouco mais liberal. Você vê um filho discutindo com o pai... mas é a cultura, nada contra. (Entrevistado de GuinéBissau, 24 anos)

Teve a primeira vez que eu vim pra a universidade, no caso pra assistir aula. Eu vim todo arrumado, do tipo que quem olhasse pra mim ia ver "caraca, esse menino é um magnata". Ai quando eu cheguei na entrada vi um monte de gente de short, de chinela, gente com regata. Foi meio estranho porque a gente lá em Angola... assim... quando a pessoa vai pra universidade a gente vai todo arrumado, sabe? As instituições obrigam, obrigam a isso. Eacho que todos os países africanos têm muito dessa lei, só que aqui no Brasil é bem mais liberal, o pessoal vai do jeito que quiser (risos). (Entrevistado de Angola, 23 anos)

O Brasil passava a ser qualificado como "liberal", em que era possível ver relações homossexuais, filhos a tratar os pais de forma "um pouco mais liberal", alunos a ir para a universidade do jeito que queriam. Ou seja, passavam a ter contato com distintas visões de mundo e formas de se comportar. Mesmo que fosse claro para eles(a) que estavam numa cultura diferente, em alguns excertos é possível ver o mal-estar que algumas situações observadas lhes provocavam. Segundo Nhaga (2013), nesses deslocamentos está também o intercâmbio de valores, em que ideias sobre determinados fatos e acontecimentos passam a ser criadas e recriadas. No caso desses interlocutores, o contato com aquilo que era "diferente" passava então a ser nomeado "como mais liberal" e dessa forma encontravam formas de conviver com aquelas "cenas", estabelecendo para eles próprios repertórios interpretativos que os faziam ter um mínimo de compreensão das realidades partilhadas, algo fundamental para estabelecer interações saudáveis no contexto em que estavam.

Da mesma forma, a imagem negativa do(a) negro(a) com a qual conviviam desencadeava interpretações particulares capaz de fazê-los criar uma explicação convincente para eles próprios sobre a discriminação racial que sofriam:

Preconceito a gente sofre todos os dias né? As cenas, tipo, aquela cena de você ser black, preto mesmo, que quando sai um negro aqui no Brasil as pessoas veem e sentem medo ... as pessoas atravessam a estrada, $e$ eu nunca me importei com isso. Eu digo até, quanto mais você se afastar, melhor. Bom é que os assaltantes também se afastam de mim. (Entrevistado de São Tomé e Príncipe, 23 anos)

Isso é um pouco chato, assim... se conformar com isso, mas agora já entendi o porquê ... A pessoa encontra você numa rua aí foge, muda de calçada, é mais por causa de ser negro e os negros são a maioria das pessoas que fazem assaltos. Ai quando veem as pessoas assim, negras, acabam confundido, aí... agora já estou um pouco mais relaxado com isso, é. Eles podem fugir de mim, mas quando eu falo com a pessoa vai dizer "ele não é daqui", ai vai querer saber mais, vai querer conversar mais, por isso que eu não ligo muito com isso, mas até hoje as pessoas fogem de mim. (Entrevistado de Guiné-Bissau, 24 anos)

Não vejo... não sei se é porque os meus olhos não veem o preconceito, sabe? Não consigo ver o preconceito assim. Mas existe, existe assim o preconceito. E eu diria que eu, pessoalmente, não sofri diretamente preconceito, mas... assim, eu já percebi algo estranho, inclusive no banco assim... a gente no banco é atendido diferente do pessoal. Mas pra mim não cabe isso como preconceito não. Pra mim... eu não sei. Se a pessoa cometer algum ato de preconceito pra mim, eu deixaria passar. Porque eu não vejo preconceito com meus próprios olhos, pra mim não existe. (Entrevistado de Cabo Verde, 27 anos)

Aqui também, no prédio onde eu moro, qualquer momento você vê esse tipo de coisa, até às vezes dentro da sala de aula. Assim... a pessoa faz sem saber, sem perceber o que tá fazendo, você... mas depois você percebe que não, isso ai foi preconceito mas foi involuntário da pessoa. Eu acho que o preconceito até que é inato, sei lá... (Entrevistada de Camarões, 27 anos)

Mesmo que elaborem argumentos contraditórios sobre o preconceito e a discriminação racial ou até tentem negar que eles existam (como podemos perceber no fragmento "não sei se é porque os meus olhos não veem o preconceito, sabe?") fica explícito que os interlocutores e a interlocutora não negam que possa haver discriminação racial no Brasil.

Todavia, numa tentativa de negociar interpretações que lhes protejam dos efeitos dessa discriminação, criam várias estratégias, seja negando para eles próprios que isso os atinge (conforme comprovamos nos fragmentos "eu nunca me importei com isso"; "mas pra mim não cabe isso como preconceito não"); seja se situando em uma posição diferenciada da categoria "negro brasileiro" e se assumindo como grupo distinto de maior estatuto"negro estrangeiro", ou ainda elaborando uma visão naturalizada da discriminação racial, como podemos ver nos fragmentos "a pessoa faz sem saber, sem 
perceber o que tá fazendo"; "Eu acho que o preconceito até que é inato, sei lá".

Essas construções discursivas indicam-nos que o fato dos próprios estudantes não refletirem sobre a discriminação racial como socialmente construída e assumir que isso os atinge acaba por preservar suas identidades enquanto negros e negra. Além disso, a provisoriedade de suas permanências no país pode contribuir para não contestarem as normas sociais ali presentes (Mourão, 2009). Também não podemos esquecer que a própria sociedade brasileira insiste no discurso de país multicultural no qual há harmonia entre pessoas de diferentes origens, o que não condiz com a hierarquia social que perpassa as classes, especialmente os grupos historicamente vulnerabilizados.

\section{Considerações finais}

Neste estudo demos protagonismo ao discurso como representativo das experiências de africanos e uma africana vinculados ao PEC-G numa instituição localizada no interior do Nordeste brasileiro. Ao escutar o que esse grupo falava sobre seus cotidianos, identificamos como os participantes mobilizavam seus discursos perante um contexto em que os veteranos africanos é que faziam o papel de agentes de socialização dos(as) calouros(as), o que gerava uma aproximação maior entre os estudantes e a estudante do mesmo continente se comparada à aproximação com brasileiros(as). Um contexto que era também qualificado como "mais liberal", em que as diferenças culturais e as representações negativas do(a) negro(a) brasileiro(a) foram apontadas pelo grupo.

É importante ressaltar que este estudo apresenta limitação no que diz respeito à especificidade do local onde foi realizada a coleta de dados, visto que trabalhamos com estudantes de apenas uma universidade localizada no Nordeste do Brasil. As percepções acerca de experiências migratórias podem variar a depender do contexto e região em que o(a) estudante estrangeiro(a) está inserido(a), já que a multiplicidade cultural do Brasil e as diferentes políticas de integração acadêmica acarretam, também, diferentes formas de acolhimento e tratamento desses(as) estudantes.

Outra limitação do estudo foi não realizar entrevista com o(a) responsável pelo PEC-G na instituição, algo que enriqueceria nossa análise sobre como a universidade se posicionava diante da integração dos(as) estudantes-convênio.

De maneira geral, a pesquisa aqui apresentada coloca em debate a migração para fins de estudo, e mais especificamente a mobilidade estudantil de africanos(as) no Brasil. Tentamos imergir em práticas discursivas que vão além de um conjunto de signos, mas que demonstram a interpretação de significados a partir de um contexto social específico. Acreditamos que esta pesquisa serviu também para provocar um debate que é muito importante para a psicologia social crítica - a migração, nomeadamente a migração temporária para fins de estudo. As peculiaridades desse fenômeno no contexto atual revelam o quão complexo ele é e o quanto é preciso problematizá-lo e desenvolver outras pesquisas em diversos contextos para que possamos avançar nessa discussão, contribuindo dessa forma para a garantia de análises que não simplifiquem os inúmeros formatos de migração.

\section{Nota}

Bolsa de estudo oferecida pelo governo brasileiro através do Programa Milton Santos de Acesso ao Ensino Superior PROMISAES (www.portal.mec.gov.br/promisaes).

\section{Referências}

Andrade, A. M. J. \& Teixeira, M. A. P. (2009). Adaptação à universidade de estudantes internacionais: um estudo com alunos de um programa de convênio. Revista Brasileira de Orientação Profissional, 10(1), 33-44.

Albuquerque, E. S. G. (2016). Aspectos cognitivos e nãocognitivos na adaptação de estudantes universitários (i) migrantes. Dissertação de Mestrado, Programa de Pósgraduação de Psicologia Cognitiva, Universidade Federal de Pernambuco, Recife.

Berry, J. W. (2004). Migração, aculturação e adaptação. In S. De Biaggi, \& G. J. Paiva (Orgs.), Psicologia, E/Imigração e Cultura (pp. 29-45). São Paulo: Casa do Psicólogo.

Berry, J. W. (2005). Acculturation: Living successfully in two cultures. International Journal of Intercultural Relations, 29, 697-712. doi: 10.1016/j.ijintrel.2005.07.013

Berry, J. W. (2006). Acculturative stress. In P. T. P. Wong \& L. C. J. Wong (Orgs.), Handbook of multicultural perspectives on stress and coping (pp. 287-298). New York: Springer.

Brisset, C., Safdar, S., Lewis, J. R., \& Sabatier, C. (2010). Psychological and sociocultural adaptation of university students in France: the case of Vietnamese international students. International Journal of Intercultural Relations, 34(4), 413-426. doi: 10.1016/j.ijintrel.2010.02.009

Brooks, R. \& Waters, J. (2011). Student mobilities, migration and the internationalization of higher education. London: Palgrave Macmillan. doi:10.1057/9780230305588

Castro, A. A. \& Cabral, A. (2012). O ensino superior: a mobilidade estudantil como estratégia de internacionalização na América Latina. Revista Lusófona de Educação,21 (21), 69-96. Acesso em 15 de novembro, 2015, em http://revistas. ulusofona.pt/index.php/rleducacao/article/view/3082

Desidério, E. J. (2005). Migração e políticas de cooperação: fluxos entre Brasil e África. In IV Encontro Nacional sobre Migração, Rio de Janeiro, Sessão Temática 1 (pp. 16-18). Sessão Temática 1. Migração Internacional, p. 23. 
Desidério, E. J. (2006). Imigração internacional com fins de estudo: o caso dos estudantes africanos do Programa Estudante Convênio de Graduação em três universidades públicas do Rio de Janeiro. Dissertação de Mestrado, Programa de Pós-graduação em Estudos Populacionais e Pesquisas Sociais, Escola Nacional de Ciências Estatísticas, IBGE, Rio de Janeiro.

Gergen, K. J. (1994). Realities and relationships. Soundings in Social construction. Cambridge: Harvard University Press.

Gergen, K. J. \& Gergen, M. (2011). Reflexiones sobre la construcción social. Barcelona: Paidós.

Gusmão, N. M. M. (2006). Trajetos identitários e negritude: jovens africanos no Brasil e em Portugal. IMPULSO, Revista de Ciências Sociais e Humanas, 17(43), 45-57.

Gusmão, N. M. M. (2008). África e Brasil no mundo acadêmico: diálogos cruzados. In Colóquio Internacional saber e poder (pp. 43-65). Campinas, SP: Focus/Unicamp.

Gusmão, N. M. M. (2009). Dossiê: Ensino superior e circulação internacional de estudantes: os Palop no Brasil e em Portugal. Pro-Posições, 20(1), 13-21. doi: http://dx.doi.org/10.1590/ $\underline{\mathrm{S} 0103-73072009000100002}$

Gusmão, N. M. M. (2012). Africanos no Brasil, Hoje: Imigrantes, refugiados e estudantes. Tomo- UFS, 21, 13-36. doi: http://dx.doi.org/10.21669/tomo.v0i21.895

_Ministério das Relações Exteriores. (2015). Divisão de temas Educacionais. PEC-G: histórico do programa. Brasília, DF: Autor. Acesso em: 15 de janeiro, 2015, em http://www.dce. mre.gov.br/PEC/G/historico.php

Mourão, D. E. (2004). Identidades em trânsito: um estudo sobre o cotidiano de estudantes guineenses e cabo-verdianos em Fortaleza. Monografia para Graduação em Ciências Sociais, Universidade Federal do Ceará, Fortaleza.

Mourão, D. E. (2009) Identidades em trânsito: África "na pasajen": identidades e nacionalidades guineenses e caboverdianas. Campinas: Arte Escrita.

Nhaga, B. (2013). Fluxos migratórios dos estudantes africanos para o Brasil: sistema de integração de estudantes africanos nas universidades públicas do nordeste (UFCG, UFPB e UFPE). Dissertação de Mestrado, Pós-graduação em Ciências Sociais, Universidade Federal de Campina Grande, PB.

Nogueira, C. (2001). Construcionismo social, discurso e gênero. Psicologia, 15(1), 43-65. Acesso em 15 de dezembro, $2016 \mathrm{em:}$ https://repositorium.sdum.uminho. pt/bitstream/1822/4039/4/construcionismo\%20social, $\% 20$ discurso $\% 20 \mathrm{e} \% 20 \mathrm{~g} \% \mathrm{C} 3 \% \mathrm{~A} 9$ nero- $\% 20$ psicologia.pdf

Nogueira, C. (2006). Os discursos das mulheres em posição de poder. Cadernos de Psicologia Social do Trabalho, 9(2), 57-72. doi: http://dx.doi.org/10.11606/issn.1981-0490. v9i2p57-72

Olwig, K. F. \& Valentim, K. (2015). Mobility, Education and Life Trajectories: New and Old Migratory Pathways. Identities: Global Studies in Culture and Power, 22(3), 247-257.

Peixoto, M. C. L. (2010). Educação como bem público, internacionalização e as perspectivas para a educação superior brasileira. In J. F. Oliveira, A. M. Catani, \& Silva, J. R. (Orgs.), Educação superior no Brasil: tempos de internacionalização (pp. 29-36). São Paulo: Xamã.

Potter, J. (1998). La representación de la realidad: discurso, retórica y construcción social. $1^{\mathrm{a}}$ ed. Buenos Aires: Paidós.

Potter, J. \& Wetherell, M. (1987). Discourse and Social Psychology: Beyond Attitudes and Behaviour. London: Sage. doi: 10.1111/j.2044-8309.1988.tb00818.x

Sarriera, J. C. (2000). Educação para a integração entre culturas e povos: da aculturação para o multiculturalismo. In
Psicologia comunitária: estudos atuais (pp. 179-202). Porto Alegre: Sulina.

Sarriera, J. C., Wagner, A., Frizzo, K. R., \& Berlim, C. S. (2002). Experiência multicultural em um grupo de conveniados africanos do programa PEC-G. Psico, 33, 447-460.

Subuhana, C. (2005). Estudar no Brasil: imigração temporária de estudantes moçambicanos do Rio de Janeiro. Tese de Doutorado, Programa de Pós-graduação em Serviço Social, Universidade Federal do Rio de Janeiro, RJ.

Subuhana, C. (2009). A experiência sociocultural de universitários da África lusófona no Brasil: entremeando histórias. Pro-Posições, 20(1), 103-126. Doi: http://dx.doi. org/10.1590/S0103-73072009000100007

Tcham, I. (2012). A Africa fora de casa: sociabilidade, trânsito e conexões entre os estudantes africanos no Brasil. Dissertação de Mestrado, Programa de Pós-graduação em Antropologia, Universidade Federal de Pernambuco, Recife, PE.

Tolentino, A. C. (2006) Universidade e Transformação Social nos Pequenos estados em desenvolvimento: o caso de Cabo Verde. Tese de Doutorado, Programa de Pós-graduação em Ciências da Educação, Universidade de Lisboa, Portugal.

Wetherell, M. \& Potter, J. (1992). Mapping the language of racism: discourse and the legitimation of exploitation. Hemel Hempstead: Harvester Wheatsheaf. doi: 10.1525/ ae.1995.22.1.02a00210

Wilks, D. C.; Monteiro, F. F. (2016). Exploring the adaptation experiences of Cape Verdean students in Portugal. International Journal of Educational Research, 76, 66-75. doi: http://dx.doi.org/10.1016/j.ijer.2016.01.002 0883-0355/ $\underline{\text { a } 2016}$

Submissão em: 07/04/2016

Revisão em : 08/12/2016

Aceite em : 07/02/2017

Luciana de Sousa Lima é licenciada em Psicologia e Pedagogia e Mestre em Educação. Está na docência do ensino de psicologia desde 2004. Atualmente faz doutoramento na Faculdade de Psicologia e Ciências da Educação da Universidade do Porto. Investiga a mobilidade estudantil de africanos/as, mais especificamente mulheres cabo-verdianas que estudam em Portugal. Vem desenvolvendo uma leitura pós-colonialista e interseccional da relação entre gênero, raça, capital escolar e mobilidades contemporâneas.

Endereço: Faculdade de Psicologia e Ciências da Educação, Universidade do Porto. Rua Alfredo Allen, 4200-135, Porto, Portugal. E-mail: lufacime@hotmail.com

Giulliany Gonçalves Feitosa é graduada em Psicologia pela Universidade Federal de Campina Grande. Atua como Psicóloga Clínica, com especial interesse na área de Saúde Mental. Atualmente cursa Especialização em Saúde Mental e Rede de Atenção Psicossocial. E-mail: giullianyg@hotmail.com 